
SIC stands for psychoana-

lytic interpretation at its

most elementary: no dis-

covery of deep, hidden

meaning, just the act of

drawing attention to the

litter-ality [sic! ] of what pre-

cedes it. A sic reminds

us that what was said, in-

clusive of its blunders, was

effectively said and cannot

be undone. The series SIC

thus explores different

connections to the Freud-

ian field. Each volume pro-

vides a bundle of Lacanian

interventions into a spe-

cific domain of ongoing

theoretical, cultural, and

ideological-political battles.

It is neither "pluralist"

A

nor "socially sensitive";

unabashedly avowing its

exclusive Lacanian orienta-

series tion, it disregards any form

edited of correctness but the

by inherent correctness of

Slavoj theory itself.

Žižek 



\section{Jacques Lacan}

Reflections on Seminar XVII and the Other Side
of Psychoanalysis

Justin Clemens

and Russell Grigg,

editors

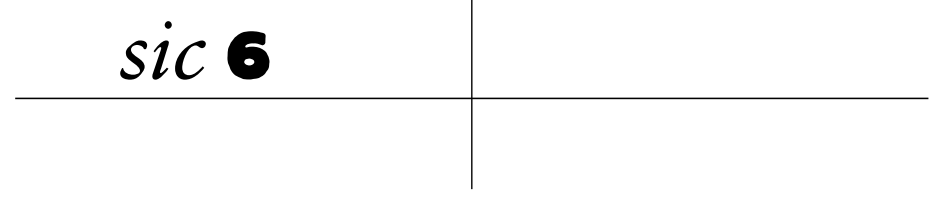

DUKE UNIVERSITY PRESS Durham and London 2006 
(C) 2006 Duke University Press

All rights reserved

Printed in the United States

of America on acid-free paper @

Typeset in Sabon by Tseng

Information Systems, Inc.

Library of Congress Cataloging-in-

Publication Data appear on the

last printed page of this book. 